\title{
Efficacy and safety of Zhibitai in combination with atorvastatin for lipid lowering in patients with coronary heart disease
}

\author{
Danyan $\mathrm{Xu}^{1,{ }^{1},}$, Jiahui $\mathrm{Hu}^{1, *}$, Qinghua Wu ${ }^{2}$, Zhiming $\mathrm{Du}^{3}$, Yusheng $\mathrm{Xue}^{4}$, Xu Zhang ${ }^{5}$, \\ Yi Li ${ }^{6}$, Yushan Chen ${ }^{7}$, Xiaoping Chen ${ }^{8}$, Hong Zhang ${ }^{9}$ and Shuiping Zhao ${ }^{10}$ \\ ${ }^{1}$ Department of Cardiology, the Second Xiangya Hospital of Central South University, Changsha, P.R. China \\ 2 Department of Cardiology, the Second Affiliated Hospital of Nanchang University, Nanchang, P.R. China \\ ${ }^{3}$ Department of Cardiology, the First Affiliated Hospital of Sun Yat-sen University, Guangzhou, P.R. China \\ ${ }^{4}$ Department of Cardiology, Tangdu Hospital, Xi'an, P.R. China \\ ${ }^{5}$ Department of Chinese Medicine, Huadong Hospital Affiliated to Fudan University, Shanghai, P.R. China \\ ${ }^{6}$ Department of Chinese Medicine, Beijing Hospital, Beijing, P.R. China \\ ${ }^{7}$ Center of Cardiology, the First Affiliated Hospital of Henan University of TCM, Zhengzhou, P.R. China \\ ${ }^{8}$ Department of Cardiology, West China Hospital of Sichuan University, Chengdu, P.R. China \\ ${ }^{9}$ Department of Cardiology, the First People's Hospital of Yunnan, Kunming, P.R. China \\ ${ }^{10}$ Department of Cardiology, the Second Xiangya Hospital of Central South University, Changsha, P.R. China \\ ${ }^{*}$ These authors were the joint first authors and have contributed equally to this work \\ Correspondence to: Shuiping Zhao, email: zhaoshuiping1@163.com \\ Keywords: Zhibitai; atorvastatin; combination therapy; dyslipidemia; atherosclerosis \\ Received: December 29, $2016 \quad$ Accepted: May 10,2017 Published: June 01, 2017
}

Copyright: Xu et al. This is an open-access article distributed under the terms of the Creative Commons Attribution License 3.0 (CC BY 3.0), which permits unrestricted use, distribution, and reproduction in any medium, provided the original author and source are credited.

\section{ABSTRACT}

Background: Zhibitai, a natural lipid-lowering Chinese medicine, is well tolerated in patients and has low incidence of adverse events. In this study, we evaluated the efficacy, safety, and side effects of Zhibitai in combination with low dose Atorvastatin compared to high dose Atorvastatin in patients with coronary heart disease or at high risk of coronary heart disease.

Methods: This was a randomized, double-blind, multi-center clinical trial on 720 patients with coronary heart disease or at high risk of coronary heart disease. The patients were randomly assigned to a Zhibitai-Atorvastatin group (480 $\mathrm{mg}$ Zhibitai twice daily plus $10 \mathrm{mg}$ atorvastatin once daily) or Monotherapy group (40 mg Atorvastatin once daily). Blood samples were obtained at baseline, week 4, and week 8 after a minimum 8-hour fast. Efficacy was evaluated in terms of the changes in the following parameters: lipoprotein profiles [total cholesterol (TC), triglyceride (TG), low-density lipoprotein cholesterol (LDL-C), high-density lipoprotein cholesterol (HDL-C)]. Safety was assessed throughout the study by clinical laboratory tests including liver function [alanine transaminase, aspartate transaminase] and renal function [blood urea nitrogen], and creatine kinase; physical examination; and adverse events monitoring.

Results: TC, TG, LDL-C levels were significantly decreased andHDL-C levels were significantly increased at week 4 and week 8 (all $P<0.05$ ) in both groups but had no significant differences between the two groups $(P>0.05)$. In subgroup analyses, Zhibitai-Atorvastatin Group produced significantly greater reduction in TG compared with Monotherapy Group at week 8 in patients with TG $>203.72 \mathrm{mg} / \mathrm{dL}(P<0.01)$. Among patients with LDL-C levels $>131.48 \mathrm{mg} / \mathrm{dL}$, Zhibitai-Atorvastatin Group produced a greater reduction of LDL-C levels compared with the Monotherapy Group at week $4(P<0.05)$. The incidence of liver dysfunction, headache, or gastrointestinal 


\begin{abstract}
intolerance was significantly lower in the Zhibitai-Atorvastatin Group compared with Monotherapy Group during the 8-week study peroid $(P<0.001)$. There were no significant differences in renal function, myopathy, and other adverse events between the groups. Conclusion: Overall the two groups have similar lipid regulation efficacy. Zhibitai plus low dose Atorvastatin is more efficacious in lowering TG in patients with TG $>\mathbf{2 0 3 . 7 2} \mathbf{~ m g}$ / dL at week 8. There are fewer side effects in Zhibitai plus low dose Atorvastatin group. Long term follow up is required to evaluate cardiovascular outcomes.
\end{abstract}

\section{INTRODUCTION}

Low-density lipoprotein cholesterol (LDL-C) reduction remains the cornerstone of atherosclerotic cardiovascular disease (ASCVD) prevention [1-2]. Statin is the primary treatment for reducing ASCVD risk for patients in whom lipid-lowering therapy is indicated [67]. European and American National Lipid Association guidelines recommend lowering LDL-C to $<69.60 \mathrm{mg} /$ dL or by $50 \%$ in patients with established ASCVD [35]. It usually requires moderate or even intensive statin to reach the target levels [8]. A range of sources support a dose relation for statin adverse events and dropouts [9-12]. Accordingly, combination low dose statin with different lipid-lowering agents to reach the recommended target levels and to reduce dose related adverse events is recommended [13].

Based on the collective evidence from several large cardiovascular outcome trials, the combination therapy with the use of Niacin [14] or Fibrates and statin didn't significantly reduce the risk of cardiovascular events but might increase serious adverse events, as compared with statin alone [15-17]. The natural lipid-lowering drugs made from Chinese Herb have fewer adverse events and are well tolerated, and would become potential alternative drugs in combination with statins in ASCVD prevention [18].

The Di'ao Zhibitai compound capsule (Zhibitai), a natural lipid-lowering Chinese medicine, is comprised of four key ingredients, hawthorn, atractylodes rhizome, alismatis rhizoma, and, Monascus spp. (also termed Red yeast rice extract). The major component of Zhibitai is a natural plant lovastatin acid, 3-hydroxy3-methylglutaryl coenzyme A (HMG-CoA) reductase. Hawthorn aids digestion, regulates blood lipoprotein, improves antioxidant, and regulates immune function. Atractylodes rhizome decreases LDL-C, increases HDL-C, and decreases anti-platelet aggregation. These components have impressive synergistic effects with different mechanisms in regulating lipoprotein levels [19]. A number of small studies have evaluated the efficacy and safety of Zhibitai compared with Atorvastatin in patients with coronary heart disease (CHD) or at high risk for CHD $[20-21,23]$. Our team has demonstrated that intensive Zhibitai therapy is as effective as Atrovastatin in lowering LDL-C, and presumably in reducing the risk of CV events [21]. Our data has also shown that Xuezhikang (a Chinese patent medicine with some same major ingredients of Zhibitai) plus low dose Rosuvastatin is more effective in lowering LDL-C levels and safer compared with high dose Rosuvastatin alone [22].

Accordingly, we propose that combined use of Zhibitai and statin is superior to statin monotherapy. Ans this study is to compare the efficacy and safety of the combination of Zhibitai and low dose Atorvastatin with high dose Atorvastatin alone in patients with $\mathrm{CHD}$ or at high risk of CHD.

\section{RESULTS}

Patients

A total of 720 patients were enrolled in the study, 10 of them were excluded due to lack of clinical laboratory lipoprotein profiles (4 patients from the ZhibitaiAtorvastatin Group, 6 patients from the Monotherapy Group) before drug administration. 353 subjects were assigned into the Zhibitai-Atorvastatin Group and 357 into the Monotherapy Group. Another 14patients were excluded after the run-in phase ( 3 patients from the Zhibitai-Atorvastatin Group; 11 patients from the Monotherapy Group) due to poor compliance or lack of information (Table 1). The difference of the dropout/elimination rate between the Zhibitai-Atorvastatin Group (1.96\%) and the Monotherapy Group (4.68\%) was significant $(P=0.0419)$, and the major reason for dropout in the Monotherapy group was poor compliance as noted in table 1. Both groups were well matched in age, sex, height, body mass index (BMI), systolic blood pressure (SBP), diastolic blood pressure (DBP), smoking status, and diabetes (Table 2).

\section{Lipid profile}

\section{Changes in lipid profile}

TC, TG, and LDL-C levels were decreased significantly at week 4 and week 8 compared with baseline in the two groups $(P<0.001)$; HDL-C levels were significantly increased compared with baseline in the two groups $(P<0.001)$. There was no significant difference between the two groups at baseline, week 4 , and week 8 
Table 1: List of excluded patients

\begin{tabular}{|l|c|l|}
\hline \multicolumn{1}{|c|}{ Group } & Total( male/female) & \multicolumn{1}{c|}{ Reasons } \\
\hline Zhibitai-Atorvastatin Group & $4(3 / 1)$ & Lacking clinical laboratory lipid profiles \\
\hline Zhibitai-Atorvastatin Group & $3(1 / 2)$ & Poor compliance \\
\hline Monotherapy Group & $6(3 / 3)$ & Lacking information of lipoprotein \\
\hline Monotherapy Group & $11(8 / 3)$ & Poor compliance \\
\hline
\end{tabular}

Table 2: Baseline characteristics of the patients (FAS)

\begin{tabular}{|l|c|c|}
\multicolumn{1}{|c|}{ Characteristics } & $\begin{array}{c}\text { Zhibitai-Atorvastatin Group } \\
(\boldsymbol{n}=\mathbf{3 5 3})\end{array}$ & $\begin{array}{c}\text { Monotherapy Group } \\
(\boldsymbol{n}=\mathbf{3 5 7})\end{array}$ \\
\hline Age, years & $58.31 \pm 9.82$ & $57.20 \pm 9.84$ \\
\hline Sex $(\mathrm{male} / \mathrm{female}), \mathrm{no}$. & $157 / 196$ & $147 / 210$ \\
\hline Height, $\mathrm{cm}$ & $164.81 \pm 7.72$ & $165.82 \pm 8.09$ \\
\hline Weight, $\mathrm{kg}$ & $66.84 \pm 10.54$ & $67.66 \pm 10.66$ \\
\hline BMI, $\mathrm{kg} / \mathrm{cm}^{2}$ & $24.55 \pm 3.04$ & $24.52 \pm 2.86$ \\
\hline SBP, $\mathrm{mmHg}$ & $135.10 \pm 17.20$ & $134.65 \pm 16.97$ \\
\hline DBP, $\mathrm{mmHg}$ & $82.53 \pm 11.16$ & $81.41 \pm 10.56$ \\
\hline Smokers, $\mathrm{no} .(\%)$ & $130(36.83)$ & $133(37.25)$ \\
\hline Patients with CHD or at high risk of CHD, no. $(\%)$ & $233(66.01)$ & $241(67.51)$ \\
\hline
\end{tabular}

BMI: body mass index; SBP: systolic blood pressure; DBP: diastolic blood pressure

Table 3: Changes in lipoprotein profiles in the two groups

\begin{tabular}{|c|c|c|c|c|c|c|}
\hline \multirow{2}{*}{ Group/Index } & \multicolumn{3}{|c|}{ Zhibitai-Atorvastatin Group $(n=353)$} & \multicolumn{3}{|c|}{ Monotherapy Group $(n=357)$} \\
\hline & Week 0 & Week 4 & Week 8 & Week 0 & Week 4 & Week 8 \\
\hline $\mathrm{TC}(\mathrm{mg} / \mathrm{dL})$ & $216.55 \pm 51.43$ & $186.39 \pm 43.31^{\mathrm{a}}$ & $170.53 \pm 40.99^{b}$ & $217.71 \pm 56.46$ & $184.45 \pm 45.63^{\mathrm{a}}$ & $169.76 \pm 41.76^{\mathrm{b}}$ \\
\hline $\mathrm{TG}(\mathrm{mg} / \mathrm{dL})$ & $232.06 \pm 134.63$ & $186.89 \pm 104.51^{\mathrm{a}}$ & $157.66 \pm 71.74^{b}$ & $232.95 \pm 143.49$ & $188.66 \pm 113.37^{\mathrm{a}}$ & $168.29 \pm 101.86^{b}$ \\
\hline $\mathrm{LDL}-\mathrm{C}(\mathrm{mg} / \mathrm{dL})$ & $128.38 \pm 41.76$ & $106.34 \pm 35.58^{\text {a }}$ & $95.24 \pm 34.48^{b}$ & $133.02 \pm 43.70$ & $107.89 \pm 37.90^{\mathrm{a}}$ & $96.64 \pm 34.42^{\mathrm{b}}$ \\
\hline $\begin{array}{l}\text { HDL-C(mg/ } \\
\text { dL) }\end{array}$ & $45.63 \pm 17.40$ & $48.72 \pm 18.17^{\mathrm{a}}$ & $51.82 \pm 16.63^{b}$ & $43.70 \pm 13.15$ & $46.79 \pm 15.85^{\text {a }}$ & $49.50 \pm 15.08^{b}$ \\
\hline
\end{tabular}

Compared with week $0,{ }^{\mathrm{a}} P<0.001,{ }^{\mathrm{b}} P<0.0001$.

TC: total cholesterol; TG: triglyceride; LDL-C: low-density lipoprotein cholesterol; HDL-C: high-density lipoprotein cholesterol

$(P>0.05)$ (Table 3).

\section{Changes in lipid profile in patients with TG $>203.72$ $\mathbf{m g} / \mathbf{d L}$}

Among patients with $\mathrm{TG}>203.72 \mathrm{mg} / \mathrm{dL}$, TG levels were significantly lower in the Zhibitai-Atorvastatin Group than in the Monotherapy Group at week $8(P<$ 0.01). Compared with baseline, TC and LDL-C levels were significantly decreased and HDL-C levels were significantly increased at week 4 and week 8 in both groups $(P<0.05)$. There was no difference between the two groups in the change of TC levels, LDL-C and HDL-C levels $(P>0.01)$ (Table 4).

\section{Changes in lipid profile in patients with LDL-C > $131.48 \mathrm{mg} / \mathrm{dL}$}

Among the patients with LDL-C $>3.4 \mathrm{mmol} / \mathrm{L}$, LDL-C, TG, and TC levels were significantly decreased, and HDL-C was significantly increased at week 4 and week 8 compared to baseline in both groups. The LDL-C was significantly lower in Zhibitai-atorvastatin Group than in the Monotherapy Group at week 4. However, the difference of LDL-C between the two groups was not significant at week $8(P>0.05)$. There was no difference of HDL-C, TG, and TC in the two groups at week 4 and week $8(P>0.05)$ (Table 5).

\section{Safety}

\section{Clinical laboratory tests}

There were no elevations of creatine kinase more than 10 times the upper limit of normal range at any time. Elevations of ALT were $4.61 \%$ and $3.22 \%$ at week 4 and week 8 respectively in the Zhibitai-Atorvastatin group and $6.98 \%$ and $10.38 \%$ at week 4 and week 8 respectively in the Monotherapy group. Elevations of AST were $3.60 \%$ and $1.90 \%$ at week 4 and week 8 respectively in the Zhibitai-Atorvastatin group and $4.71 \%$ and $8.28 \%$ at week 4 and week 8 respectively in the Monotherapy group. There were no significant differences in renal 
Table 4: Changes in lipoprotein profiles in patients with TG $>\mathbf{2 0 3 . 7 2 m g / d L ~}$

\begin{tabular}{|l|c|c|c|c|c|c|}
\hline \multirow{2}{*}{ Group/Index } & \multicolumn{3}{|c|}{ Zhibitai-Atorvastatin Group $(n=181)$} & \multicolumn{3}{c|}{ Monotherapy Group(n=175) } \\
\cline { 2 - 7 } & Week 0 & Week 4 & Week 8 & Week 0 & Week 4 & Week 8 \\
\hline TC $(\mathrm{mg} / \mathrm{dL})$ & $226.60 \pm 52.59$ & $192.58 \pm 42.92^{\mathrm{b}}$ & $174.01 \pm 39.44^{\mathrm{b}}$ & $235.89 \pm 55.29$ & $196.06 \pm 48.72^{\mathrm{c}}$ & $179.25 \pm 42.54^{\mathrm{c}}$ \\
\hline $\mathrm{TG}(\mathrm{mg} / \mathrm{dL})$ & $317.09 \pm 137.29$ & $230.23 \pm 106.29^{\mathrm{b}}$ & $186.01 \pm 80.60^{\mathrm{a}, \mathrm{b}}$ & $325.07 \pm 154.12$ & $250.67 \pm 130.20^{\mathrm{c}}$ & $216.12 \pm 122.23^{\mathrm{c}}$ \\
\hline $\begin{array}{l}\mathrm{LDL}-\mathrm{C}(\mathrm{mg} / \\
\text { dL) }\end{array}$ & $130.70 \pm 41.76$ & $105.18 \pm 34.42^{\mathrm{b}}$ & $93.58 \pm 32.10^{\mathrm{b}}$ & $141.53 \pm 44.86$ & $113.69 \pm 40.60^{\mathrm{c}}$ & $99.77 \pm 36.74^{\mathrm{c}}$ \\
\hline HDL-C(mg/d) & $44.08 \pm 15.85$ & $48.72 \pm 19.72^{\mathrm{b}}$ & $51.82 \pm 15.47^{\mathrm{b}}$ & $42.54 \pm 10.83$ & $46.79 \pm 11.99^{\mathrm{c}}$ & $49.88 \pm 15.47^{\mathrm{c}}$ \\
\hline
\end{tabular}

Compared to Monotherapy Group, ${ }^{\mathrm{a}} P<0.01$; Compared to Zhibitai-Atrovastatin Group at week $0,{ }^{\mathrm{b}} P<0.05$; Compared to Monotherapy Group at week $0,{ }^{c} P<0.05$.

TC: total cholesterol; TG: triglyceride; LDL-C: low-density lipoprotein cholesterol; HDL-C: high-density lipoprotein cholesterol.

Table 5: Changes in lipid profiles in patients with $\mathrm{LDL}-\mathrm{C}>131.48 \mathrm{mg} / \mathrm{dL}$

\begin{tabular}{|l|l|l|l|l|l|c|}
\hline \multirow{2}{*}{ Group/Index } & \multicolumn{3}{|c|}{ Zhibitai-Atorvastatin Group $(\boldsymbol{n}=\mathbf{1 7 2})$} & \multicolumn{3}{c|}{ Monotherapy Group $(\boldsymbol{n}=\mathbf{1 7 0})$} \\
\cline { 2 - 7 } & \multicolumn{1}{|c|}{ Week 0 } & \multicolumn{1}{c|}{ Week 4 } & Week 8 & \multicolumn{1}{c|}{ Week 0 } & Week 4 & Week 8 \\
\hline $\mathrm{TC}(\mathrm{mg} / \mathrm{dL})$ & $243.23 \pm 36.74$ & $199.15 \pm 40.99^{\mathrm{b}}$ & $182.91 \pm 41.76^{\mathrm{c}}$ & $250.58 \pm 45.63$ & $206.88 \pm 44.08^{\mathrm{b}}$ & $187.16 \pm 41.38^{\mathrm{c}}$ \\
\hline $\mathrm{TG}(\mathrm{mg} / \mathrm{dL})$ & $231.18 \pm 132.86$ & $185.12 \pm 103.63^{\mathrm{b}}$ & $155.00 \pm 66.43^{\mathrm{c}}$ & $246.24 \pm 138.18$ & $200.18 \pm 118.69^{\mathrm{b}}$ & $170.95 \pm 85.92^{\mathrm{c}}$ \\
\hline $\mathrm{LDL}-\mathrm{C}(\mathrm{mg} / \mathrm{dL})$ & $162.03 \pm 25.14$ & $122.20 \pm 34.03^{\mathrm{a}, \mathrm{b}}$ & $108.28 \pm 33.64^{\mathrm{c}}$ & $168.21 \pm 30.94$ & $129.93 \pm 36.74^{\mathrm{b}}$ & $113.69 \pm 34.80^{\mathrm{c}}$ \\
\hline $\mathrm{HDL}-\mathrm{C}(\mathrm{mg} / \mathrm{dL})$ & $46.84 \pm 14.31$ & $48.72 \pm 12.76^{\mathrm{b}}$ & $52.59 \pm 15.08^{\mathrm{c}}$ & $45.63 \pm 12.76$ & $49.88 \pm 18.95^{\mathrm{b}}$ & $53.36 \pm 17.03^{\mathrm{c}}$ \\
\hline
\end{tabular}

Compared to Monotherapy Group at week $4,{ }^{\mathrm{a}} P<0.05$; Compared to Zhibitai-Atrovastatin Group at week 0 , ${ }^{\mathrm{b}} P<0.05$; Compared to Monotherapy Group at week $0,{ }^{c} P<0.05$.

TC: total cholesterol; TG: triglyceride; LDL-C: low-density lipoprotein cholesterol; HDL-C: high-density lipoprotein cholesterol.

Table 6: Occurrence of abnormal clinical laboratory tests [no. (\%)]

\begin{tabular}{|l|c|c|c|c|c|c|}
\hline \multirow{2}{*}{ Group/Index } & \multicolumn{2}{|c|}{ Zhibitai-Atorvastatin Group $(\boldsymbol{n}=\mathbf{3 5 3})$} & \multicolumn{3}{c|}{ Monotherapy Group $(\boldsymbol{n}=357)$} \\
\cline { 2 - 7 } & Week 0 & Week 4 & Week 8 & Week 0 & Week 4 & Week 8 \\
\hline ALT(abnormal) & $0(0.00)$ & $14(4.61)$ & $10(3.22)^{\mathrm{a}}$ & $0(0.00)$ & $21(6.98)$ & $30(10.38)^{\mathrm{a}}$ \\
\hline AST(abnormal) & $0(0.00)$ & $11(3.60)$ & $6(1.90)^{\mathrm{b}}$ & $0(0.00)$ & $14(4.71)$ & $24(8.28)^{\mathrm{b}}$ \\
\hline BUN(abnormal) & $0(0.00)$ & $9(3.38)$ & $9(3.20)$ & $0(0.00)$ & $7(2.31)$ & $15(5.08)$ \\
\hline Creatine(abnormal) & $0(0.00)$ & $6(2.21)$ & $7(2.46)$ & $0(0.00)$ & $6(1.96)$ & $9(3.00)$ \\
\hline CK(abnormal) & $0(0.00)$ & $5(2.39)$ & $9(4.37)$ & $0(0.00)$ & $5(2.42)$ & $7(3.52)$ \\
\hline
\end{tabular}

Compared with Monotherapy Group at week $8,{ }^{a} P<0.001,{ }^{b} P<0.001$. ALT: Alanine transaminase (the definition of ALT abnormal was $>3$ times the upper limit of normal range); AST: aspartate transaminase (the definition of ALT abnormal was $>3$ times the upper limit of normal

range); BUN: blood urea nitrogen (the definition of BUN abnormal was $>$ the upper limit of normal range); CK: creatine kinase (the definition

of ALT abnormal was $>10$ times the upper limit of normal range).

function and CK between the two groups $(P>0.05)$ (Table 6). Elevations of ALT and AST were lower in ZhibitaiAtorvastation Group than Atorvastatin Group both in subgroup $\mathrm{TG}>203.72 \mathrm{mg} / \mathrm{dL}$ and subgroup LDL-C > $131.48 \mathrm{mg} / \mathrm{dL}$ with the same results as the entire study population. (Supplementary Table 1 and Supplementary Table 2).

\section{Adverse events}

There were no serious adverse events and adverse events were rare. The incidence of gastrointestinal intolerance was $0.28 \%$ vs. $7.63 \%$ at week 4 and $0.28 \%$ vs. $7.39 \%$ at week 8 in the two groups as noted in table 7 . The 
Table 7: Occurrence of side effects [no. (\%)]

\begin{tabular}{|l|c|c|c|c|c|c|}
\hline \multirow{2}{*}{ Group/Side effects } & \multicolumn{3}{|c|}{ Zhibitai-Atorvastatin Group } & \multicolumn{3}{c|}{ Monotherapy Group } \\
\cline { 2 - 7 } & $\begin{array}{c}\text { Week 0 } \\
(\boldsymbol{n}=\mathbf{3 5 3})\end{array}$ & $\begin{array}{c}\text { Week 4 } \\
(\boldsymbol{n}=\mathbf{3 5 3})\end{array}$ & $\begin{array}{c}\text { Week 8 } \\
(\boldsymbol{n}=\mathbf{3 5 1})\end{array}$ & $\begin{array}{c}\text { Week 0 } \\
(\boldsymbol{n}=\mathbf{3 5 7})\end{array}$ & $\begin{array}{c}\text { Week 4 } \\
(\boldsymbol{n}=\mathbf{3 5 4})\end{array}$ & $\begin{array}{c}\text { Week 8 } \\
(\boldsymbol{n}=352)\end{array}$ \\
\hline Insomnia & $30(8.5 \%)$ & $22(6.23 \%)$ & $12(4.27 \%)$ & $21(5.88 \%)$ & $19(5.73 \%)$ & $16(4.55 \%)$ \\
\hline Depression & $6(1.7 \%)$ & $1(0.28 \%)$ & $0(0.00 \%)$ & $5(1.41 \%)$ & $5(1.41 \%)$ & $3(0.85 \%)$ \\
\hline Dyspepsia & $10(2.83 \%)$ & $7(1.98 \%)$ & $6(1.71 \%)$ & $14(3.92 \%)$ & $14(3.95 \%)$ & $12(3.41 \%)$ \\
\hline Diarrhea & $2(0.57 \%)$ & $0(0.00 \%)$ & $0(0.00 \%)^{\mathrm{a}}$ & $4(1.12 \%)$ & $7(1.98 \%)$ & $7(1.99 \%)$ \\
\hline Nausea & $4(1.13 \%)$ & $1(0.28 \%)$ & $1(0.28 \%)^{\mathrm{a}}$ & $8(2.24 \%)$ & $20(5.65 \%)$ & $19(5.40 \%)$ \\
\hline Headache & $7(1.98 \%)$ & $3(0.85 \%)$ & $2(0.57 \%)^{\mathrm{a}}$ & $12(3.36 \%)$ & $12(3.47 \%)$ & $9(2.60 \%)$ \\
\hline Coelialgia & $1(0.28 \%)$ & $0(0.00 \%)$ & $3(0.86 \%)^{\mathrm{a}}$ & $10(2.80 \%)$ & $11(3.17 \%)$ & $8(2.31 \%)$ \\
\hline Myalgia & $0(0.00 \%)$ & $0(0.00 \%)$ & $0(0.00 \%)^{\mathrm{a}} \%$ & $8(2.24 \%)$ & $10(2.89 \%)$ & $8(2.31 \%)$ \\
\hline Others & $2(0.57 \%)$ & $3(0.85 \%)$ & $2(0.57 \%)$ & $0(0.00 \%)$ & $1(0.28 \%)$ & $0(0.00 \%)$ \\
\hline
\end{tabular}

Compared with Monotherapy Group at week $8,{ }^{a} P<0.001$

incidence of headache was $0.85 \%$ vs. 3.47 at week 4 and $0.57 \%$ vs. $2.60 \%$ at week 8 in the two groupd respectively) $(P<0.05)$. There was no difference of incidence of insomnia, depression, dyspepsia, and other adverse events in the two groups. There was some difference in the incidence of stomachache and myalgia at baseline and at week 4 and week 8 , but the changes have no significant differences (all, $P>0.05$ ) (Table 7).

\section{DISCUSSION}

TC, TG, and LDL-C levels were significantly decreased and HDL-C levels were significantly increased at 4 and 8 weeks in the Zhibutai-Atorvastatin Group and Monotherapy Group. In subgroup analyses, TG levels were significantly lower at week 8 in the ZhibitaiAtorvastatin Group than in the Monotherapy Group among patients with TG $>203.72 \mathrm{mg} / \mathrm{dL}$, and LDL-C levels were significantly lower at week 4 in the Zhibitai-Atorvastatin Group than in the Monotherapy Group among patients with LDL-C > $131.48 \mathrm{mg} / \mathrm{dL}$.

Our group previously has demonstrated that compared with $10 \mathrm{mg}$ atorvastatin, $480 \mathrm{mg}$ Zhibitai (twice daily), equal dosage of this research, could also decrease LDL-C, TG, TC level after 8 weeks of treatment, and the difference between these two groups had no statistically significance [22]. Further research of Xiang [24] also have found that $480 \mathrm{mg}$ Zhibitai (twice daily) was equal to $10 \mathrm{mg}$ atorvastatin in lowering TC, TG and LDL-C level, and rising HDL-C level. This research and ours reflected that 480mg Zhibitai twice daily had equal effect in regulating lipoprotein levels compared to $10 \mathrm{mg}$ atorvastatin.

It is well known that statins could increase protein convertase subtilisin/kexin type 9 (PCSK9) protein levels, which binds the hepatic LDL-C receptor (LDLR), causing LDLR subsequent degradation and then increasing circulating LDL-C level [25-29]. So increasing dose of statins failed to achieve propotional LDL-C lowering and the descend range of LDL-C only increased 5\%-6\% with the dosage doubling.

In subgroup of LDL-C $>131.48 \mathrm{mg} / \mathrm{dL}$, ZhibitaiAtorvastatin Group showed advantage in lowering LDL-C levels comparing with Monotherapy at week 4. So our initial idea was that better effect of Zhibitai in lowering LDL-C level might be due to Zhibitai-induced decreasing in PCSK9 levels.

First, we have proved that statin could up-regulate the expression of PCSK9 level with dose-independent manner (Supplementary Figure 1). Then, Zhibitai was used to challenge starving HepG2 cells, but what made us surprised was that PCSK9 was also increased with the increasing dosage of Zhibitai (Supplementary Figure 2), which means the better efficacy of Zhibitai-Atorvastatin therapy in lowering LDL-C level didn't rely on decreasing PCSK9.

Then whether there exists another pathway of Zhibitai in lowering LDL-C level. The sterol-responsive nuclear liver X receptor (LXR) helps maintain cholesterol homeostasis, not only through promotion of cholesterol efflux but also through suppression of low-density lipoprotein (LDL) uptake. LXR inhibits the LDL receptor (LDLR) pathway through transcriptional induction of Idol (inducible degrader of the LDLR), an E3 ubiquitin ligase that triggers ubiquitination of the LDLR on its cytoplasmic domain, thereby targeting it for degradation [39]. So in our following research, we detected the expression of LXR, a specific element in the upstream related to Idol. However, it was shown no down-regulation of LXR with increasing dosage of Zhibitai (Supplementary Figure 3), means that the target of Zhibitai was not LXR-Idol-LDLR axis either

The Chinese medicine Zhibitai capsule is comprised of monacolins, hawthorn, alismatis, and atractylodes 
rhizome. The four components in Zhibitai have synergistic effect in regulating lipoprotein levels and the mechanism of Zhibitai remains to be further studied [30-32].

Previous research by our group proved that 480 mg Zhibitai therapy significantly decreases plasma TG at week 4 , while $10 \mathrm{mg}$ atorvastatin only decreases TG at week 8. From this small-scale study, Zhibitai-Atrovastatin can reduce TG levels more than high dose Atrovastin among patients with $\mathrm{TG}>203.72 \mathrm{mg} / \mathrm{dL}$ at week 8 , which indicates Zhibitai may be more effective in reducing TG than Atorvastatin. In addition to the natural statin, monacolins, Zhibitai also contains linoleic acid (which comprises $48.13 \%$ of the total fatty acids in Zhibitai), which might contribute to reducing TG levels [33-34] .The benefit of lowering TG would provide an option to Asian patients who mainly have hypertriglyceridemia and who favor traditional Chinese medicine.

Our study also shows that Zhibitai-atorvastatin is better at lowering LDL-C levels compared with Atorvastatin alone in patients with LDL-C $>131.48$ $\mathrm{mg} / \mathrm{dL} \mathrm{mmol} / \mathrm{L}$ at week 4 . The hawthorn component in Zhibitai contains ursolic acid and oleanolic acid, which can also decrease LDL-C [35]. Alismatis can decrease TC, TG, and LDL-C levels by reducing fat absorption from the intestine and cholesterol synthesis in the liver, and promote insulin release and decreases glucose levels [36]. These components have a synergistic effect on regulating lipoprotein levels [19].

There were fewer adverse events in the ZhibitaiAtorvastatin Group and lower incidence of liver dysfunction compared with high dose of Atorvastatin. Gastrointestinal intolerance is less in the ZhibitaiAtorvastatin group. The hawthorn in Zhibitai capsules aids digestion and has a positive effect on blood lipid profiles. Zhibitai capsules are comprised of common Chinese traditional medicines that are safely manufactured and approved by China Food and Drug Administration. All components in the Zhibitai capsules are commonly used, safe, and non-toxic and are widely used in some food preparations. In the present study, the incidence of adverse events in the the Zhibitai-Atrovastatin group was lower. The Zhibitai capsules were well tolerated and easily accepted by the patients with a better compliance.

The follow-up period of this study is only up to 8 weeks, which is not long enough to show the cardiovascular outcomes. Long term follow up will be required to provide the evidence of the combination therapy with the use of Zhibitai and low-dose Atorvastatin in the reduction of the risk of cardiovascular events.

The LDL-C, TC, and TG levels in both groups were decreased effectively. However, the combination of Zhibitai and Atorvastatin was more effective in lowering TG and LDL-C levels in patients with hypertriglyceridemia and with LDL-C $>131.48 \mathrm{mg} / \mathrm{dL}$ $\mathrm{mmol} / \mathrm{L}$. Zhibitai plus atorvastatin was effective, safe, and well tolerated.

\section{MATERIALS AND METHODS}

\section{Study patients}

A total of 720 patients ( 310 men and 410 women) aged 25-89 years with CHD or at high risk of CHD were enrolled from 11 medical centers between 2011 and 2012.

The diagnosis of CHD or at high risk of CHD was made according to the Chinese guidelines on the prevention and treatment of dyslipidemia in adults as follows: (1) CHD was defined as acute coronary disease, including unstable angina (UA), acute myocardial infarction (AMI), stable angina pectoris, old MI, myocardial ischemia with objective evidence, and following percutaneous coronary intervention or coronary artery surgery; (2) ischemic stroke, peripheral arterial disease, abdominal aortic aneurysm, symptomatic carotid artery disease, and diabetes, multiple risk factors (hypertension, smoking, obesity, male $\geq 45$ years old or female $\geq 55$ years old with first-degree relative with $\mathrm{CV}$ diseases, or male $\geq 55$ years old or female $\geq 65$ years old); and (3) major adverse coronary events equivalent to CHD. [13, 37-38]

The subjects must fulfill one of the following inclusion criteria to be eligible for participation: (1) TC > $200.31 \mathrm{mg} / \mathrm{dL}$ or LDL-C $>130.32 \mathrm{mg} / \mathrm{dL}$; (2) TG level $>$ $150.58 \mathrm{mg} / \mathrm{dL}$; (3) HDL-C $<40.22 \mathrm{mg} / \mathrm{dL}$.

The exclusion criteria were: (1) MI within 3 months of study recruitment, cerebrovascular accidents within 6 months, severe trauma or major surgery, nephritic syndrome (NE), hypothyreosis, acute or chronic hepatobiliary disease and familial hypercholesterolemia; (2) hyperlipidemia caused by drugs such as phenothiazine, adrenergic beta blockers, cortical hormones, and acyeterion; (3) taking heparin, anti-thyroid drugs, or other drugs that would affect serum lipid metabolism; (4) pregnant or nursing women, statin and Zhibitai allergy, or psychosis; (6) poor cardiac function, i.e., grade IV according to the New York Heart Association (NYHA).

\section{Research methodology}

\section{Study design}

This was a randomized, controlled, double-blind, multi-center clinical trial. 720 patients were randomly assigned in a 1:1 ratio into the Zhibitai-Atorvastatin Group ( $n=357$, age $58.31 \pm 9.82$ years, 160 men and 197 women) or the Monotherapy Group $(n=363$, age $57.69 \pm 9.87$ years, 150 men and 213 women). During the 8 week study period, patients in the Zhibitai-Atorvastatin Group received $480 \mathrm{mg}$ of Zhibitai (manufactured by Chendu Di'ao Pharmaceutical Group Co., Ltd.) twice daily and $10 \mathrm{mg}$ of Atorvastatin once daily; patients in 
the Monotherapy Group received $40 \mathrm{mg}$ of Atorvastatin once daily. The research ethics committee of Central South University approved the study. Each patient provided written informed consent.

\section{Efficacy and safety assessment}

During the double-blind period, the efficacy was evaluated by measuring TC, TG, HDL-C, and LDL-C levels at baseline, week 4 , and week 8 respectively. Safety was assessed by clinical laboratory tests including alanine transaminase (ALT), aspartate transaminase (AST), creatine, blood urea nitrogen (BUN), creatine kinase (CK); physical examination; and adverse events monitoring. Blood samples were collected after a minimum 8-hour fast.

\section{Statistical analysis}

All statistical analyses were performed using SAS software (version 9.13) for Windows. The chisquare test, Student's $t$-test, or nonparametric test was used to compare the baseline characteristiics (mean \pm SD or medians) at baseline; Student's $t$-test was used to analyze the lipoprotein profiles at any time point of the two groups as well as for self-comparison. Repeated measures analysis of covariance (REANCOVA) was used to analyze the lipoprotein profiles, including $\mathrm{TG}, \mathrm{TC}$, LDL-C, and HDL-C levels. ANCOVA was used to analyze the LDL-C levels in the TG $>2.3 \mathrm{mmol} / \mathrm{L}$ subgroup, and the chi-square test was used to compare the changes in safety profiles. For all outcomes, a $P$-value of 0.05 was considered to indicate statistical significance, and all tests were two-sided.

\section{CONCLUSIONS}

This clinical strudy provides evidence that combination therapy with the use of Zhibitai and low dose of Atorvastatin is safe, effective, and well-tolerated in reducing LDL-C and TG in patients with $\mathrm{CHD}$ or at high risk of CHD. The study suggests that the combination of the use of Zhibitai and low-dose Atorvastatin is potentially more efficacious in reducing LDL-C and TG and has fewer adverse events resulting in better patients' compliance compared with high dose of Atorvastatin alone.

\section{Abbreviations}

CHD: coronary heart disease ASCVD: atherosclerotic cardiovascular disease; UA: unstable angina AMI: acute myocardial infarction; TC: total cholesterol; TG: triglyceride; LDL-C: low-density lipoprotein cholesterol HDL-C: high-density lipoprotein cholesterol; ALT: alanine transaminase AST: aspartate transaminase; BUN: blood urea nitrogen $\mathrm{CK}$ : creatine kinase; NE: nephritic syndrome NYHA: the New York Heart Association; BMI: body mass index SBP: systolic blood pressure; DBP: diastolic blood pressure HMGCoA: hydroxymethylglutaryl coenzyme A; PCSK9: protein convertase subtilisin/kexin type 9; SREBP-2: sterol regulatory element-binding protein-2; REANCOVA: Repeated measures analysis of covariance.

\section{CONFLICTS OF INTEREST}

All authors declare that they have no any conflict of interests.

\section{FUNDING}

This study was supported by grant from the National Nature Science Foundation of China( NSFC, No.81372117 and 81672264)

\section{REFERENCES}

1. Zhao D, Liu J, Xie W, Qi Y. Cardiovascular risk assessment: a global perspective. Nature Reviews Cardiology. 2015; 12: 301-311.

2. Third Report of the National Cholesterol Education Program (NCEP) Expert Panel on Detection, Evaluation, and Treatment of High Blood Cholesterol in Adults (Adult Treatment Panel III) final report. Circulation. 2002; 106: 3143.

3. Cholesterol Treatment Trialists' (CTT) Collaboration. Efficacy and safety of more intensive lowering of LDL cholesterol: a meta-analysis of data from 170,000 participants in 26 randomised trials. Lancet. 2010; 376: 1670.

4. Smith SC Jr, Benjamin EJ, Bonow RO, Braun LT, Creager MA, Franklin BA, Gibbons RJ, Grundy SM, Hiratzka LF, Jones DW, Lloyd-Jones DM, Minissian M, Mosca $\mathrm{L}$, et al. AHA/ACCF secondary prevention and risk reduction therapy for patients with coronary and other atherosclerotic vascular disease: 2011 update: a guideline from the American Heart Association and American College of Cardiology Foundation endorsed by the World Heart Federation and the Preventive Cardiovascular Nurses Association. Journal of the American College of Cardiology. 2015; 65: 1495.

5. Catapano AL, Graham I, De Backer G, Wiklund O, Chapman MJ, Drexel H, Hoes AW, Jennings CS, Landmesser U, Pedersen TR, Reiner Ž, Riccardi G, Taskinen MR, et al. ESC/EAS Guidelines for the Management of Dyslipidaemias: The Task Force for the management of dyslipidaemias of the European Society of Cardiology (ESC) and the European Atherosclerosis Society (EAS) Developed with the special contribution of 
the European Assocciation for Cardiovascular Prevention \& Rehabilitation (EACPR). European Heart Journal. 2016; 217: 3-46.

6. Baigent C, Keech A, Kearney PM, Blackwell L, Buck G, Pollicino C, Kirby A, Sourjina T, Peto R, Collins R, Simes R, and Cholesterol Treatment Trialists' (CTT) Collaborators. Efficacy and safety of cholesterol-lowering treatment: prospective meta-analysis of data from 90056 participants in 14 randomised trials of statins. Lancet. 2005; 366: 1267-1278.

7. Kashani A, Phillips CO, Foody JM, Wang Y, Mangalmurti S, Ko DT, Krumholz HM. Risks associated with statin therapy:a systematic overview of randomized clinical trials. Circulation. 2006; 114: 2788-2797.

8. Pitt B, Waters D, Brown WV, van Boven AJ, Schwartz L, Title LM, Eisenberg D, Shurzinske L, McCormick LS. Aggressive lipid-lowering therapy compared with angioplasty in stable coronary artery disease. Atorvastatin versus Revascularization Treatment Investigators. New England Journal Medicine. 1999; 341: 70-76.

9. Wang Y, Wei Q. Muscle adverse effect and solutions of statin. Strait Pharmaceutical Journal. 2008; 20: 131.

10. Zhang X, Zhang J, Fang Y. Clinical study of atorvastatin on carotid artery atherosclerotic plaques in patients with cerebral infraction. Chinese Journal of Practical Nervous Disease. 2007; 10: 13.

11. Du X, Lahm S, Zhu X, Sun H, Liu LM, Jian LY. Adverse reactions of atorvastatin. Herald of Medicine. 2011; 30: 1528-1530.

12. Preiss D, Seshasai SR, Welsh P, Murphy SA, Ho JE, Waters DD, DeMicco DA, Barter P, Cannon CP, Sabatine MS, Braunwald E, Kastelein JJ, de Lemos JA, et al. Risk of incident diabetes with intensive-dose compared with moderate-dose statin therapy: a meta-analysis. JAMA. 2011; 305: 2556-2564.

13. Joint committee for developing Chinese guidelines on prevention and treatment of dyslipidemia in adults. Chinese guidelines on prevention and treatment of dyslipidemia in adults. Chinese Circulation Journal. 2016; 31: 937-953.

14. Executive summary of the Third Report of the National Cholesterol Education Program (NCEP) Expert Panel on Detection, Evaluation, and Treatment of High Blood Cholesterol in Adults. JAMA. 2001; 285: 2486-2497.

15. Ginsberg HN, Elam MB, Lovato LC, Crouse JR 3rd, Leiter LA, Linz P, Friedewald WT, Buse JB, Gerstein HC, Probstfield J, Grimm RH, Ismail-Beigi F, Bigger JT, et al, and ACCORD Study Group. Effects of combination lipid therapy in type 2 diabetes mellitus. New England Journal Medicine. 2010; 362: 1563-1574.

16. Boden WE, Probstfield JL, Anderson T, Chaitman BR, Desvignes-Nickens P, Koprowicz K, McBride R, Teo $\mathrm{K}$, Weintraub W, and AIM-HIGH Investigators. Niacin in patients with low HDL cholesterol levels receiving intensive statin therapy. New England Journal Medicine.
2011; 365: 2255-2267.

17. Landray MJ, Haynes R, Hopewell JC, Parish S, Aung T, Tomson J, Wallendszus K, Craig M, Jiang L, Collins R, Armitage J, and HPS2-THRIVE Collaborative Group. Effects of extended-release niacin with laropiprant in highrisk patients. New England Journal Medicine. 2014; 371: 203-212.

18. $\mathrm{Lu} \mathrm{ZH,} \mathrm{Fu} \mathrm{X.} \mathrm{A} \mathrm{clinical} \mathrm{study} \mathrm{of} \mathrm{hyperlipemia} \mathrm{by}$ simvastatin combined shanzha jiangzhi decoction therapy. Journal of Liaoning University of TCM. 2009; 11: 113-114.

19. Chang WT, Dao J, Shao ZH. Hawthorn: potential roles in cardiovascular disease. Am J Chin Med. 2005; 33: 1-10.

20. Wang $\mathrm{L}, \mathrm{Wu} \mathrm{JL}, \mathrm{Wu} \mathrm{QP}$. Research and application progress of red yeast rice for lowering the blood chelosterol level. Science and Technology of Food Industry. 2014; 35: 387393.

21. Xu DY, Shu J, Huang QY, Chen C, Liu L, Zhao SP. Comparative study of the efficacy and safety of Zhibitai and atorvastatin. China Journal of Internal Medicine. 2010; 49: 392-395.

22. Zhang ML, Duan ZW, Xie SM. Study on Bioactive Constituents of Xuezhikang. China Academic Journal Electronic Publishing House. 1998; 213.

23. Hao YP. Observation of curative effect of zhibitai in treating hyperlipidemia. Chinese Journal of Practical Nervous Disease. 2013; 16: 77-78.

24. Xiang W. Observation of curative effect of zhibitai capsules in 40 patients with dislipidemia. Journal of Hubei University of Science and Technology (Medicine Science). 2013; 27: 320-322.

25. Scharnagl H, Schinker R, Gierens H, Nauck M, Wieland H, März W. Effect of atorvastatin, simvastatin, and lovastatin on the metabolism of cholesterol and triacylglycerides in HepG2 cells. Biochem Pharmacol. 2001; 62: 1545-1555.

26. Jones P, Kafonek S, Laurora I, Hunninghake D. Comparative dose efficacy study of atorvastatin versus simvastatin, pravastatin, lovastatin, and fluvastatin in patients with hypercholesterolemia (the CURVES study). The American Journal of Cardiology. 1998; 81: 582-587.

27. Von Schacky C, Harris WS. Cardiovascular benefits of omega-3 fatty acids. Cardiovascular Research. 2007; 73: 310-315.

28. Zhang Y, Liu J, Li S, Xu RX, Sun J, Li JJ. Impact of currently prescribed lipid-lowering drugs on plasma PCSK9 concentration: single or in combination study in rats. Lipids in health and disease. 2014; 13: 35.

29. Dubuc G, Chamberland A, Wassef H, Davignon J, Seidah NG, Bernier L, Prat A. Statins upregulate PCSK9, the gene encoding the proprotein convertase neural apoptosis-regulated conveitase-1 implicated in familial hypercholesterolemia. Arterioscler Thromb Vase Biol. 2004; 24: 1454-1459.

30. Zheng B, Wei J, Jiang J, Gong HH, Zhang RS. The therapeutic effects of combination of simvastatin with 
berberine on the patients with hyperlipemia. ACTA Unieversitys Medicinalis Nanjing (Natural Science). 2009; 29: 1493-1497.

31. Li S. Effect of Xuezhikang,an extract from red yeast Chinese rice on coronary events in a Chinese population with previous myocardial infarction. Am J Cardiol. 2008; 101: 1689-1693.

32. Li JJ, Lu ZL, Kou WR, Chen Z, Wu YF, Zhao YC, and Chinese Coronary Secondary Prevention Study Group. Impact of Xuezhikang on coronary events in hypertensive patients with previous myocardial infarction from the China Coronary Secondary Prevention Study (CCSPS). Ann Med. 2010; 42: 231-240.

33. Wang $\mathrm{L}, \mathrm{Wu} \mathrm{JL}, \mathrm{Wu}$ QP. Research and application progress of red yeast rice for lowering the blood cholesterol level. Science and Technology of Food Industry. 2014; 35: 387 389.

34. Patrick L, Uzick M. Cardiovascular disease: C-reactive protein and the inflammatory disease paradigm: HMG-CoA reductase inhibitors, alpha-tocopherol, red yeast rice, and olive oil polyphenols. A review of the literature. Altern Med Rev. 2001; 6: 248-271.

35. Wu SJ, Li QJ, Xiao XF, Li M, Yang XR, Lu T. Research on the chemical components and pharmacological effects of hawthorn. Drug Evaluation Research. 2010; 33: 316-319.
36. Yu J, Ye H, Lin X. Reviews of pharmacological studies on alismatis. Strait Pharmaceutical Journal. 2011; 23: 92-93.

37. Rosenson RS, Baker SK, Jacobson TA, Kopecky SL, Parker BA, The National Lipid Association's Muscle Safety Expert Panel. An assessment by the Statin Muscle Safety Task Force: 2014 update. Journal of Clinical Lipidology. 2014; 8: S58-S71.

38. Stroes ES, Thompson PD, Corsini A, Vladutiu GD, Raal FJ, Ray KK, Roden M, Stein E, Tokgözoğlu L, Nordestgaard BG, Bruckert E, De Backer G, Krauss RM, et al. Statinassociated muscle symptoms: impact on statin therapyEuropean Atherosclerosis Society Consensus Panel Statement on Assessment, Aetiology and Management. European Heart Journal. 2015; 36: 1012-1022.

39. Zelcer N, Hong C, Boyadjian R, Tontonoz P. LXR regulates cholesterol uptake through Idol-dependent ubiquitination of the LDL receptor. Science. 2009; 325: 100-104. 